\title{
A SYSTEMATIC LITERATURE REVIEW OF COMMUNICATION STRATEGIES AND MENSTRUAL HYGIENE: FROM 2007 TO 2020.
}

\author{
Nidhi Sharma \\ PhD Research Scholar, University Institute of Media Studies, Chandigarh University, Punjab, India. \\ E-mail: nidhiphd2019@gmail.com \\ Fakira Mohan Nahak \\ Professor, University Institute of Media Studies, Chandigarh University, Punjab, India. \\ E-mail: mohan.fakir@gmail.com
}

\begin{abstract}
Adolescence is a transitional stage between the childhood and adulthood where one faces so many physical, psychological, social and cultural pressures. Due to the unset of the menstrual cycle, most of the adolescent girls go through anxiety, fear and stigma in this phase of life. With an objective to conduct a systematic literature review of existing studies on menstrual hygiene and MHHM (Menstrual Health and Hygiene Model) this study is undertaken and by this the researchers have tried to identify major gaps in existing studies of all over the world. Menstrual hygiene is a precautionary measure to overcome the taboo of menstruation among young girls. The researchers conducted SLR with help of Google scholar and PubMed to explore different research articles related to MHHM (Menstrual Health \& Hygiene Model) until December 2020. The study applied PRISMA technique on 390 research studies retrieved from Google Scholar and PubMed and only 40 papers were selected for final review. From the study it is found that, majority of the studies are conducted in developing countries from Asia and Africa. But contrary to this most of these studies are conducted by scholars/researchers from developed countries. Only $20 \%$ of studies are from developed countries like USA and western European countries. One of the major findings of the study is that most of the research studies lack a proper theoretical framework and not used any theory or model. The present study will help the researchers to focus on the specific geographic regions where major studies are not conducted on menstrual health and hygiene. Similarly it will further encourage the researchers to go for qualitative studies and developing proper theoretical frameworks and follow proper communication models for the research study.
\end{abstract}

Keywords: menstruation, menstrual health, hygiene management, communication pattern

\section{INTRODUCTION}

Menstruation is a natural and biological process but more than that it has become a social and cultural taboo. Mostly women faced social discrimination, deep -rooted social and cultures gullible and gender based inequalities during their menstruation (Mukherjee, et al, 2020). Nobody want to discuss this issue openly because of that it creates dilemma in minds of adolescents. So this situation leads to many reproductive health problems among adolescent girls especially in developing and underdeveloped countries (Hennegan J, et al, 2019).This important issue should be highlighted through health communication, under which we should discuss preventive and precautionary measures along with extension education (Sharma N, et al, 2019). Firstly we should understand who is an adolescent? WHO-The World Health Organization clearly defines adolescents as young people in the age group of 10 to 19 year and they cover around $16 \%$ population of whole world (WHO, 2002). Especially adolescent girls face one of the major changes in their body and that is menstruation during this time (Haque SE, et al 2014). Young girls are mostly hesitating to discuss their menstruation problem with their parents, teachers and relatives (Pandey N, 2020). Sometime that leads to misinformation and misconceptions of menstruation and menstruation hygiene practices among adolescents. Menstruation and its related hygiene practices still considered a taboo. There are so many social and cultural restrictions imposed on women (Rajagopal S, Mathur K, 2017). Hygiene related practices during menstruation are very important, as an ignorance of various sanitation practices leads to increased susceptibility to reproductive tract infectionsRTI (Das A, 2014). RTI is becoming a silent 
epidemic among women due to negligence of hygiene practices; they use unhygienic clothes and other dirty practices that lead to major health problems (Singh S, et al, 2011). Major reason behind this problem is lack of communication and unawareness about scientific facts. Menstrual hygiene should be an important and integral part of health education specifically for young girls, so that they develop an attitude of maintaining hygiene throughout their life (Dasgupta $M$, 2008). In every educational institution there should be a structure of effective communication with adolescent girls, so that they get right information from right place at right time. Through valuable interpersonal communication, young girls to adult women can escape from the problem of RTI and its consequences (Anand E, et al, 2015). Most of the adolescent girls get their firsthand information regarding menstruation and its hygiene related issues from their mothers, teachers, friends, relatives and mass media like television (Haque SE, et al. 2014). The mothers also lack awareness and techniques to communicate information to their daughters regarding menstruation and its hygiene, which is a major obstacle to convey scientific information (Crichton J, et al 2012). Another important point, too many myths related to menstrual hygiene exists in society which creates many taboo and fear among teenagers and adolescents (Garg R, et al 2012). Due to social and cultural pressure, their attitude and perceptions towards menstrual hygiene practices are very negative, that can be reasons of many reproductive health problems among adolescents (Zaidi SHN, et al. 2015; Kumar A. \& Srivastava K. 2011). In developing countries like India, most of the adolescent girls are affected by reproductive health problems and that may affect the usual life of teenagers (Santhya, K.G. et al 2017). Communication gaps and many social and cultural restrictions create psychological, mental, physical and behavioral pressures which become reasons of reproductive problems (Rajagopal S. et al 2017). During their menarche, the first time flow of blood generate anxiety and fear among teenagers because their society and culture have already made their mind negative and discourage them for open discussion (C. Susila, et al. 2014; Kumar A. \& Srivastava K. (2011). There is a majority of research studies conducted on menstrual health and hygiene in developing or underdeveloped countries, but less focus is on developed countries. Similarly there is a number studies which lack basic theories and models of communication.

\section{OBJECTIVES}

- To analyze different communication strategies of menstrual health and hygiene and various menstrual health practices.

- To identify the major gaps in research studies on menstrual health and hygiene conducted across the globe.

\section{THEORETICAL FRAME OF REFERENCES}

The current study analyzes all major research papers related to menstrual hygiene and practices along with communication strategies of menstrual health and hygiene management (MHHM). It explored different theories and models in various research articles which deeply define characteristics of studies. The major theories and models are as followed.

\subsection{Grounded theory}

The Grounded theory is one of the mostly used theories in qualitative researches. In order to construct the theory it encompasses a systematic, inductive and comparative approach for conducting inquiry (Charmaz, 2006; Charmaz and Henwood 2007). The Grounded theory method (GTM) analyzed whole qualitative data through codes and summarizes into the idea or concept, we can say abstract of whole content and explains relationship between them. Grounded theory can be defined in following way-

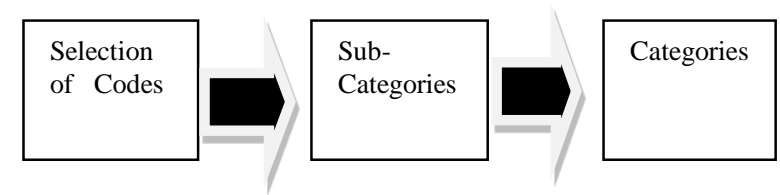

It is a systematic method of data analysis. This theory based on original data and ignored preconceived idea or concepts. Best part of grounded theory is based on objectivity and positivist assumptions. The positivist paradigm assumes a true reality that helpful to attain objective of research (Guba and Lincoln, 2005).

\subsection{Health Belief Model}

Health belief model (HMB) is social and psychological model which discussed health pattern and health perceptions of people. HMB is another extensively researched model 
of health behavior (Hochbaum and Rosenstock, 1952). In 1950 this model was originated as a systematic method to explain and predict preventive health behavior (Cheraghi, Poorolajal, Hazavehi, and Rezapur-Shahkolai, 2014; Murray-Johnson et al.2005).Firstly we should understand the concept of health education; it means to acquire knowledge, information and awareness about health at individual and organizational level. HBM model to helpful to analyzed health behavior of people, according to that policy maker can set agenda of health education. There are levels which influenced to health-related conditions and behaviors.

Health belief model is theoretical model which helpful to promote health related material and disease preventions program in community. It is widely used for predict health behaviors of individuals as well as organizational level. So with the help of these factors, HBM is one of the models used to encourage health and precautionary behaviors such as nutritional behaviors, in regard to the complex and real links between attitudes, beliefs and behaviors, health education, and health promotion models (Glanz K. 2008). All health awareness campaign should be implemented with consideration of HBM; so that people positive and negative reactions related to health related policies or decisions could be considerable and timely motivate to people to avoid unconstructive consequences of their health beliefs.

\subsection{Multilevel Health Education Model}

Multilevel health education model (MHEM) is one of the models which evaluated social, cultural and economic factors which framed health beliefs. MHEM is based on $5 \mathrm{w}$ of communication include who (message communicator), what (health message), how (channel), to whom (target audience/ human behavior) and consider all creative health designs and messages which impress the human behavior. It can be define following way -

\subsection{Social Learning Theory}

Social learning is behavioral theory which proposed by Albert Bandura. It has evaluated human behavior through social learning and behavior is analyzing through observation, audience reactions along with their attitude. SLT is a psychological path to learning about human relationship. It is an educational program which is based on surrounding. SLT is helpful to planning health promotional
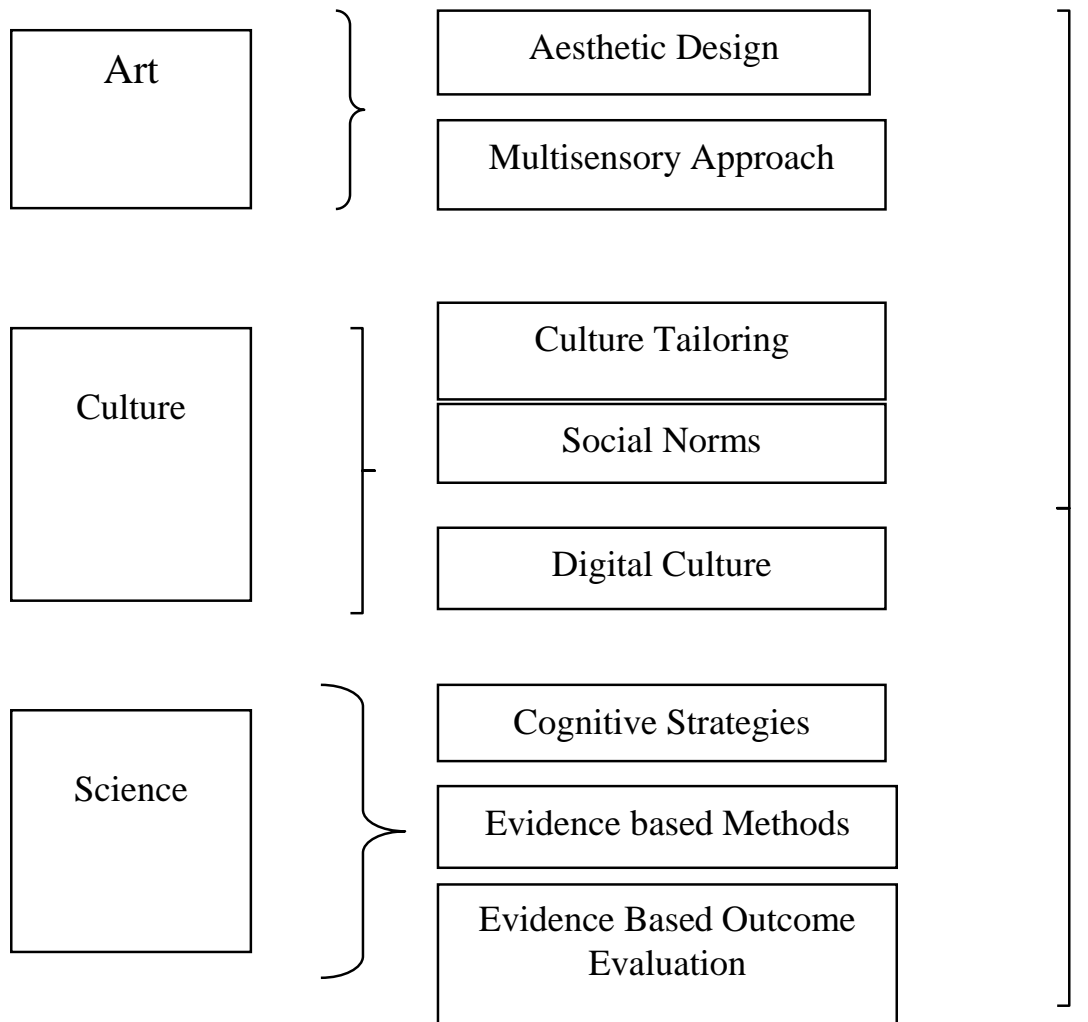
Health Education \& Behavior Change

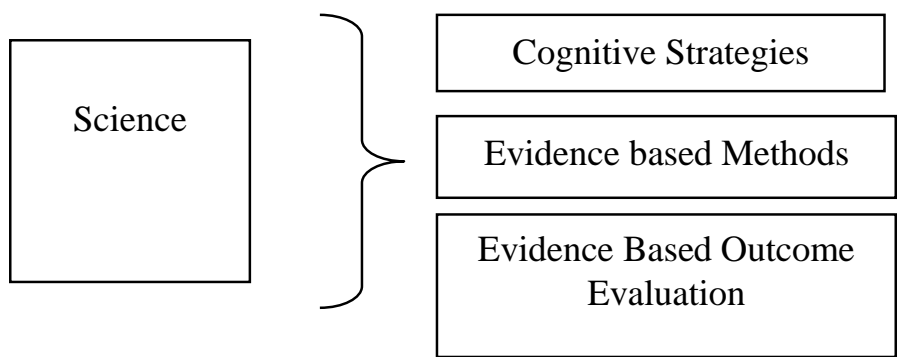

Source - (O.willaims et al 2019). https://www.ncbi.nlm.nih.gov/pmc/articles/PMC6427730/ 
programs, it is useful to access number of target audience, their needs, interest of audience in health matters, perception about their health beliefs and ratio of acceptance innovative or new health policies. (Rosenstock, 1988).

\subsection{Social Cognitive Theory}

In the 1960s, the development of social cognitive theory takes shape. Bandura's bestknown cognitive version of social learning theory, social cognition theory (SCT), elaborates human behavior in a three-way interaction between behavior, environmental influence and personal variables..(Bullen\& Roberts, 2018) , \& Morgan, 2014).

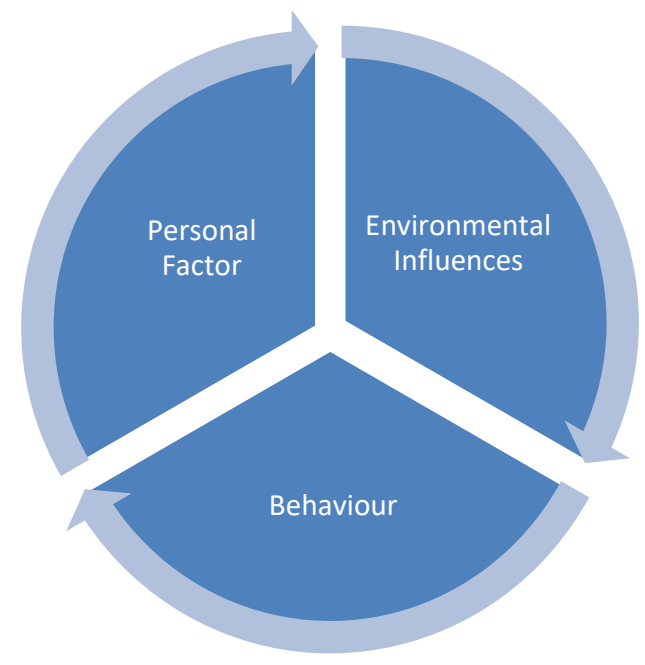

Source - Bandura, A.,(1986). Social Foundations of Thought and Action: A Social Cognitive Theory. Prentice-Hall.P.24.

When it comes to assessing health behavior change, social cognitive theory comes in handy. People must take several steps in completing the goal behavior (self-efficacy) and believe that the conduct will benefit them in the long run, according to SCT (outcome expectancies). Interventions usually teach skills that assist people begin and continue PA activities while also altering the social and physical environment to help the target behavior rather than inhibit it (Glanz \& Bishop, 2010). The authors concluded that SCT is a viable framework for explaining Personal audience behavior in a study published in
2014. Models of higher quality explained more PA variance, but methodological quality was poor overall (Glanz \& Bishop, 2010). Highquality SCT studies for PA are required (Young et al., 2014). SCT-based therapies were also helpful in modifying diet and physical activity and 58 habits, according to a metaanalysis and comprehensive review of 18 trials on cancer survivors (Stacey et al., 2015).

\section{RESEARCH METHODS AND TECHNIQUES}

The current study is a systematic review of various literatures on health awareness of menstrual health and hygiene appeared in different national and international journals\& databases in last thirteen years. A systematic literature review is a method for conducting an in-depth survey or analysis of prior research studies in a certain field or area of study. This provides researchers with an inside look into various phenomena in a certain subject, as well as objectives, research questions, conceptual assessments of different relevant theories, research procedures used, and analysis completed within a specific time frame. This aids a researcher in identifying gaps and new dimensions from which a new researcher might begin his or her inquiry. This SLR will give a comprehensive review of previous research on menstruation and menstruation hygiene habits in India and abroad. This review study is specifically concerned with various channels of communication and their significance in menstrual awareness, health agenda setting, behavior theories, and so on. This research has aided the researcher in determining a future course of action for further studies in the field of the role of the media in creating mass awareness in the domain of menstrual hygiene awareness.

The research papers and articles were chosen from a variety of journals on PubMed and Google Scholar, with a focus on open access journals in India. Menstrual hygiene, menstrual hygiene management, the Health Belief Model, and social learning are all topics covered in the selected research studies. Menstrual awareness, Menstrual Hygiene Management, and Role of Media in promoting awareness among adolescents were commonly searched on these data to reorganize the most appropriate research paper on the above- 
mentioned domains for the primary research and article selection.

\subsection{Coding And Classification}

The researchers defined the research to analyze articles published in the last thirteen years from 2007 to 2020 on the above stipulated, due to the journal's specific focus on health-related issues and behavioral change theories and model related all components, after adapting the procedures presented (Junior L and Filho G, 2010). Researchers chose 40 research papers for this study. As shown in Table-1, the researchers first conducted a study of the articles, providing few aspects and respective citations are collected from Google Scholar and PubMed. 'Menstrual,' 'Menstrual Hygiene,' 'Menstrual Hygiene Management,' 'Reproductive education,' and 'Communication strategies of MHHM' were among the keywords used in Google Scholar and PubMed to find publications relevant to the study. For the selection of research publications, the PRISMA recommendations are followed.

The goal of the entire investigation is to determine the contribution and influence that the papers had on the academic field. Throughout this study, the researcher followed the arrangement and numbering of the papers in Table -1 . They evaluated the concerns raised by the authors, evaluating their influence and contribution to a better understanding of the relationship between menstrual health hygiene management and behavioral change theories and models, based on their specialization.

Table 1 shows the article classification, which includes nine large subjects numbered from 1 to 9 and categorized by letters ranging from $\mathrm{A}$ to J. Aside from that, depending on the extent of the studies examined, an article may obtain more than one code.

The first classification involves identifying the context analyzed by the articles. It presented the countries where researches were conducted.

The categories were divided into three parts A, B and C under Developed, Developing/Emerging countries and non- applicable means that some particular articles do not fall under any of subcategories.

The second classification refers to identify the geographic region of the research countries with codes from $A$ to $G$, where studies are conducted. This showed the researchers to specially study the countries where research on menstrual health and hygiene practices were conducted. With codes ranging from A to $\mathrm{D}$,

the third classification shows the items' purpose. This classification is based on the articles' objective. For example, scholars have determined if the study was concerned with a conceptual examination of the theme or if it was related to literature reviews and comparative studies in this classification.

The fourth categorization, which was coded from $A$ to $G$, focused on the major theme of the articles in relation to the main subject studied in the research. This classification is closely related to the knowledge of which subject areas have been researched.

The fifth classification deals with different theories and models which were used in different research articles coded with letters A to $\mathrm{F}$.

The sixth classification relates to methods that were used in different articles, coded by letters A to E. This classification helped to know what methods are more important in the study of different articles.

The seventh classification emphasizes on the major topics of the articles, classified with letters from A to J. They highlighted important topics and sub-topics which covered in different research papers.

The eighth classification deals with the period of different studies, coded by letters A to F. It was the period of time had taken by the researchers to simplifying problem with conclusions.

Lastly, ninth classification focused on results and conclusions which coded by letters $\mathrm{A}$ to $\mathrm{F}$. Researchers highlighted outcomes with future line of actions. 
Table 1- Categories and subcategories used for analysis

\begin{tabular}{|c|c|c|}
\hline Category & Meaning & Codes of Alternatives \\
\hline 1 & Context & $\begin{array}{l}\text { A-Developed countries } \\
\text { B-Developing or emerging countries } \\
\text { C-Non - applicable }\end{array}$ \\
\hline 2 & Geographic Region & $\begin{array}{l}\text { A -United states of America } \\
\text { B- Europe } \\
\text { C-Asia } \\
\text { D-Middle East } \\
\text { E-Africa } \\
\text { F-Other countries } \\
\text { G-Non-applicable }\end{array}$ \\
\hline 3 & Objectives & $\begin{array}{l}\text { A- Conceptually contributes to the subject } \\
\text { B- Literature Review } \\
\text { C-Present Case study } \\
\text { D - Non-applicable }\end{array}$ \\
\hline 4 & Main Subject & $\begin{array}{l}\text { A-Related to access awareness level of menstrual hygiene } \\
\text { B- Related to menstruation } \\
\text { C- Related to menstrual hygiene management } \\
\text { D -Related to social and cultural beliefs of menstruation } \\
\text { E-Related to attitude of adolescents towards menstruation } \\
\text { F-Related to reproductive health education. } \\
\text { G-Non-applicable }\end{array}$ \\
\hline 5. & $\begin{array}{l}\text { Theories and models } \\
\text { used }\end{array}$ & $\begin{array}{l}\text { A-Grounded theory } \\
\text { B-Health Belief Model } \\
\text { C-Multilevel Health Education Model } \\
\text { D-Social learning } \\
\text { E-Social Cognitive } \\
\text { F-Non- applicable }\end{array}$ \\
\hline 6. & Method & $\begin{array}{l}\text { A - Cross-sectional study } \\
\text { B- Quantitative } \\
\text { C- Qualitative } \\
\text { D-Hybrid (Combination of both quantitative and qualitative } \\
\text { analysis) } \\
\text { E-Non-applicable }\end{array}$ \\
\hline 7. & Topics & $\begin{array}{l}\text { A- Understand Menstrual Hygiene. } \\
\text { B -Knowledge level from menarche to menopause } \\
\text { C-Analysis perception and attitude towards menstruation. } \\
\text { D-Initiative towards menstrual hygiene practices. } \\
\text { E-To understand social and cultural beliefs for menstruation. } \\
\text { F- Parents belief about menstruation } \\
\text { G-Role of MHHM to changing beliefs and perception of } \\
\text { adolescents. } \\
\text { H-Parents-Adolescents communication } \\
\text { I-School level awareness mechanism about MHM } \\
\text { J- Others }\end{array}$ \\
\hline 8. & Analysis Period & $\begin{array}{l}\text { A- Less than } 1 \text { years } \\
\text { B- } 1-2 \text { years } \\
\text { C-3-5 years } \\
\text { D- } 6 \text { - } 10 \text { years } \\
\text { E-More than } 10 \text { years } \\
\text { F- Non-applicable }\end{array}$ \\
\hline
\end{tabular}




\begin{tabular}{|l|l|l|}
\hline 9. & A- Proper implementation of MHHM in educational \\
& & institutions \\
& B- Better communication between teachers and adolescents \\
& C- Promote reproductive health education \\
& D- Communication campaign should be framed with \\
& E- $\begin{array}{l}\text { Mensideration of social and cultural perspectives } \\
\text { instinct of adolescents. } \\
\end{array}$ \\
& F- Others \\
\hline
\end{tabular}

(Source: We have written these words)

\subsection{Results and Discussion}

This section presents the final results of the present research study. Afterwards, the outcomes are discussed to analyze and reach to conclusions and identify major research gaps for future research recommendations.

\section{Coding -}

This section presents the categorization of all 40 articles with respect to each of the classification and coding shown in Table 2.

Table 2- Data classification and categorization

\begin{tabular}{|c|c|c|c|c|c|c|c|c|c|}
\hline S.N. & Context & $\begin{array}{c}\text { Geographic } \\
\text { Region }\end{array}$ & Objectives & $\begin{array}{c}\text { Main } \\
\text { Subject }\end{array}$ & $\begin{array}{c}\text { Theories/ } \\
\text { Models }\end{array}$ & Methods & Topics & $\begin{array}{l}\text { Analysis } \\
\text { Period }\end{array}$ & Results \\
\hline 1 & B & $\mathrm{C}$ & $\mathrm{B}$ & $\mathrm{C}$ & $\mathrm{D}$ & $\mathrm{C}$ & $\mathrm{L}$ & $\mathrm{D}$ & $\mathrm{A}$ \\
\hline 2 & B & C & A & E & B & A & E & $\mathrm{A}$ & $\mathrm{D}$ \\
\hline 3 & B & C & A & B & C & B & C & A & C \\
\hline 4 & B & C & A & $\mathrm{E}$ & $E$ & B & C & $\mathrm{A}$ & C \\
\hline 5 & $\mathrm{~B}$ & $\mathrm{C}$ & $\mathrm{A}$ & $\mathrm{C}$ & $\mathrm{B}$ & $\mathrm{C}, \mathrm{D}$ & $\mathrm{E}$ & $\mathrm{B}$ & $\mathrm{A}$ \\
\hline 6 & B & $\mathrm{C}$ & A & $\mathrm{D}$ & $\mathrm{B}, \mathrm{D}$ & $\mathrm{A}$ & $\mathrm{H}$ & $\mathrm{A}$ & $\mathrm{A}$ \\
\hline 7 & B & $\mathrm{C}$ & $\mathrm{A}$ & $\mathrm{E}$ & $\mathrm{B}, \mathrm{E}$ & B & $E$ & $\mathrm{~A}$ & B \\
\hline 8 & B & $\mathrm{C}$ & $\mathrm{A}, \mathrm{C}$ & $\mathrm{A}, \mathrm{F}$ & $\mathrm{B}$ & $\mathrm{D}$ & I & $\mathrm{A}$ & $\mathrm{C}$ \\
\hline 9 & B & $\mathrm{C}$ & $\mathrm{A}$ & $\mathrm{B}$ & B & $\mathrm{D}$ & $E$ & $\mathrm{~A}$ & $\mathrm{D}, \mathrm{E}$ \\
\hline 10 & B & $\mathrm{C}$ & A & $\mathrm{B}, \mathrm{C}$ & $\mathrm{B}, \mathrm{C}$ & $\mathrm{A}, \mathrm{B}$ & $\mathrm{A}, \mathrm{E}$ & $\mathrm{A}$ & B \\
\hline 11 & B & $\mathrm{D}$ & A & $\mathrm{E}$ & $\mathrm{B}, \mathrm{E}$ & $\mathrm{A}$ & $\mathrm{H}$ & $\mathrm{A}$ & $\mathrm{A}$ \\
\hline 12 & $\mathrm{~A}$ & $E$ & $\mathrm{~B}$ & $\mathrm{~A}$ & $\mathrm{E}$ & $\mathrm{C}$ & $\mathrm{C}, \mathrm{H}$ & $\mathrm{D}$ & $\mathrm{A}$ \\
\hline 13 & $\mathrm{~B}$ & $\mathrm{D}$ & $\mathrm{A}, \mathrm{C}$ & $\mathrm{E}$ & $\mathrm{D}, \mathrm{E}$ & $\mathrm{C}$ & $\mathrm{H}$ & $\mathrm{C}$ & $\mathrm{A}$ \\
\hline 14 & A & B & $\mathrm{A}, \mathrm{C}$ & A & $\mathrm{E}$ & $\mathrm{C}$ & $\mathrm{A}, \mathrm{E}$ & B & A \\
\hline 15 & B & C & $\mathrm{A}$ & C & $\mathrm{D}$ & $\mathrm{A}$ & $\mathrm{C}$ & $\mathrm{A}$ & $\mathrm{A}$ \\
\hline 16 & $\mathrm{~B}$ & $\mathrm{E}$ & $\mathrm{A}, \mathrm{C}$ & $F$ & $E$ & C,D & $\mathrm{D}$ & $\mathrm{A}$ & $\mathrm{A}$ \\
\hline 17 & A & $\mathrm{A}$ & $\mathrm{C}$ & A & B & $\mathrm{D}$ & $\mathrm{E}, \mathrm{G}$ & B & $\mathrm{D}$ \\
\hline 18 & B & $\mathrm{E}$ & C & C & E & C & $\mathrm{H}$ & B & $\mathrm{A}$ \\
\hline 19 & B & E & C & $\mathrm{A}$ & $E$ & B & $\mathrm{B}, \mathrm{F}$ & $\mathrm{A}$ & $\mathrm{A}$ \\
\hline 20 & B & $E$ & $\mathrm{C}$ & $\mathrm{A}, \mathrm{E}$ & B & B & $\mathrm{B}$ & $\mathrm{A}$ & $\mathrm{A}$ \\
\hline 21 & B & C & $\mathrm{A}$ & $\mathrm{D}$ & $\mathrm{D}$ & C, & $\mathrm{C}$ & $\mathrm{A}$ & $\mathrm{A}$ \\
\hline 22 & C, & E & $\mathrm{A}, \mathrm{C}$ & $\mathrm{A}, \mathrm{D}$ & $\mathrm{C}$ & $\mathrm{D}$ & $\mathrm{A}, \mathrm{H}$ & A & A \\
\hline 23 & C & E & $\mathrm{C}$ & B & $\mathrm{A}, \mathrm{C}$ & $\mathrm{D}$ & $\mathrm{D}, \mathrm{I}$ & A & E \\
\hline 24 & B & $\mathrm{C}$ & $\mathrm{A}$ & B & $\mathrm{B}, \mathrm{C}$ & $\mathrm{A}$ & $\mathrm{B}, \mathrm{F}$ & $\mathrm{A}$ & $E$ \\
\hline 25 & B & $\mathrm{C}$ & $\mathrm{A}, \mathrm{C}$ & $\mathrm{B}, \mathrm{C}$ & $\mathrm{E}$ & $\mathrm{D}$ & $\mathrm{D}, \mathrm{E}$ & $\mathrm{A}$ & A \\
\hline 26 & B & C & $\mathrm{A}, \mathrm{C}$ & B,D & E & A & $\mathrm{D}, \mathrm{E}$ & A & $\mathrm{A}$ \\
\hline 27 & B & C & $\mathrm{A}$ & $\mathrm{A}, \mathrm{C}$ & B & $\mathrm{A}$ & B,D & A & $\mathrm{A}$ \\
\hline 28 & B & $\mathrm{D}$ & $\mathrm{A}$ & $\mathrm{A}$ & B & B & $\mathrm{B}, \mathrm{D}, \mathrm{H}$ & B & $\mathrm{A}, \mathrm{B}$ \\
\hline 29 & B & C & $\mathrm{A}, \mathrm{C}$ & $\mathrm{D}$ & $\mathrm{E}$ & $\mathrm{D}$ & $C, D, E$ & $\mathrm{~A}$ & $\mathrm{~A}, \mathrm{~B}$ \\
\hline 30 & B & E & $\mathrm{A}, \mathrm{C}$ & E & $\mathrm{E}$ & $\mathrm{D}$ & $\mathrm{D}, \mathrm{E}$ & $\mathrm{A}$ & $\mathrm{A}, \mathrm{C}$ \\
\hline 31 & B & $\mathrm{C}$ & $\mathrm{A}, \mathrm{C}$ & $\mathrm{F}$ & E & $\mathrm{D}$ & $\mathrm{C}, \mathrm{D}, \mathrm{G}$ & B & $\mathrm{A}, \mathrm{B}, \mathrm{D}$ \\
\hline 32 & B & $E$ & $\mathrm{~A}$ & $\mathrm{~A}, \mathrm{~B}$ & B & B & $\mathrm{A}, \mathrm{D}$ & B & $\mathrm{A}, \mathrm{C}$ \\
\hline 33 & A & $\mathrm{A}$ & $\mathrm{A}$ & $\mathrm{A}, \mathrm{B}$ & $\mathrm{A}, \mathrm{B}$ & $\mathrm{D}$ & $\mathrm{B}, \mathrm{C}, \mathrm{D}$ & B & $\mathrm{C}$ \\
\hline 34 & B & $\mathrm{E}$ & $\mathrm{A}, \mathrm{C}$ & $\mathrm{C}$ & $\mathrm{B}, \mathrm{C}$ & A & $\mathrm{A}, \mathrm{D}$ & A & $\mathrm{A}, \mathrm{E}$ \\
\hline 35 & B & $\mathrm{C}$ & $\mathrm{A}$ & $\mathrm{A}, \mathrm{F}$ & $\mathrm{B}$ & $\mathrm{B}$ & $\mathrm{D}$ & $\mathrm{A}$ & $\mathrm{A}$ \\
\hline 36 & B & C & $\mathrm{A}, \mathrm{C}$ & B & $\mathrm{C}, \mathrm{D}$ & $\mathrm{A}, \mathrm{D}$ & $E$ & B & $E$ \\
\hline 37 & $\mathrm{~A}$ & B & B & $\mathrm{A}$ & $\mathrm{A}, \mathrm{B}$ & $\mathrm{C}$ & $\mathrm{D}$ & $\mathrm{D}$ & $E$ \\
\hline 38 & C & E & A & A & $\mathrm{B}, \mathrm{C}$ & $\mathrm{D}$ & C & B & A \\
\hline 39 & B & $\mathrm{C}$ & $\mathrm{A}$ & $\mathrm{D}$ & $\mathrm{B}, \mathrm{E}$ & B & I & B & C \\
\hline 40 & B & $\mathrm{E}$ & $\mathrm{A}$ & $\mathrm{F}$ & $\mathrm{B}$ & $\mathrm{D}$ & $\mathrm{F}$ & B & $\mathrm{E}$ \\
\hline
\end{tabular}


1. Context - The first category identified the context of research articles, which coded from A to C.

A- Developed Countries

B- Developing Countries

C- Non-applicable

The results of the classification are shown in the following graph

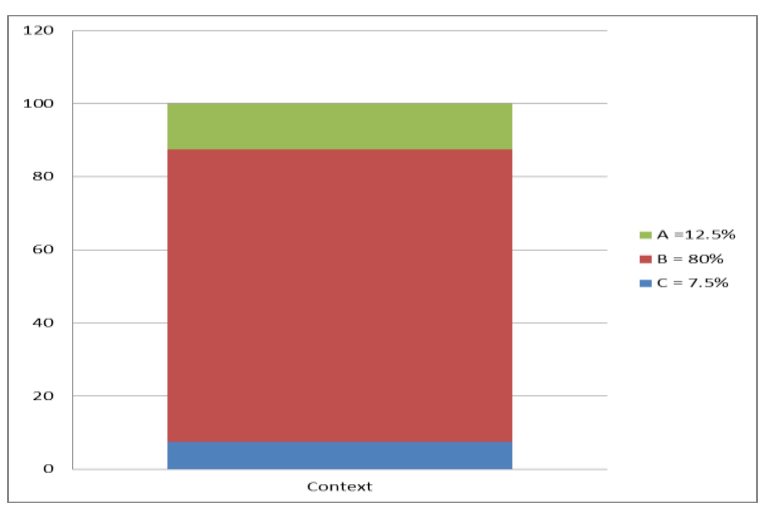

Figure - 1 (Source: We have written this)

It is clear from the graph (Figure-1) that $80 \%$ research articles focused on developing or emerging countries which are mostly Asian and African countries. One thing to be noted that these studies were conducted by scholar from developed countries along with developing countries researchers. Researchers have availed only $12.5 \%$ research articles from developed countries include USA as well as Western Europe and rest $7.5 \%$ in nonapplicable (c) category which include all underdeveloped countries. The findings clearly showed that more research in subject area was conducted in developing countries compared to develop and underdeveloped countries.

Gap 1: Need of more research in underdeveloped counties.

2. Geographic Region: The second classification focuses on defining the countries' unique geographic regions. These countries are classified as following
A -United states of America
B- Europe
C-Asia
D-Middle East
E-Africa
F-Other countries
G-Non-applicable

The results of the classification are shown in the following graph-

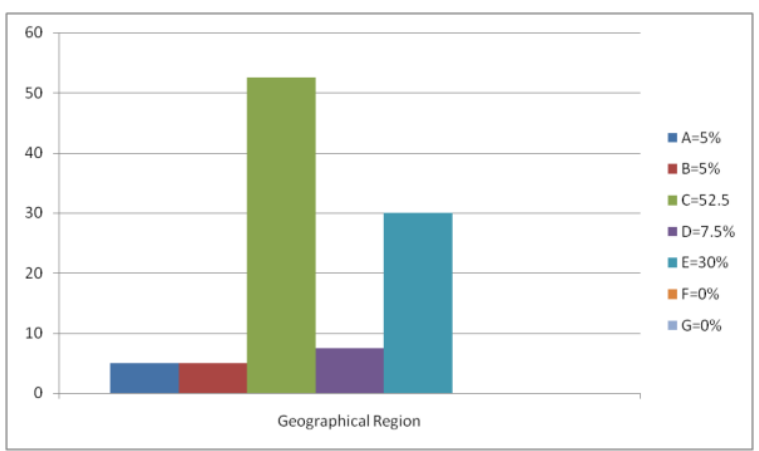

Figure - 2 (Source: We have written this)

The Figure-2 showed the classification of geographical regions where studies were conducted. Researchers found $52.5 \%$ studies from Asian countries and $30 \%$ studies from African countries (E) and rest studies from Europe, USA and middle east countries. But distribution as well as research studies focused on only particular geographical region, rest of those need to be explored for research topic.

Gap 2: specifically nations from a specific region need to be studied deeply where not too much research is being conducted on the subject area.

3. Objectives: The third classification deal with the objective of the various articles. The code are explained following way -

A- Conceptually contributes to the subject B- Literature Review

C-Present Case study

D - Non-applicable

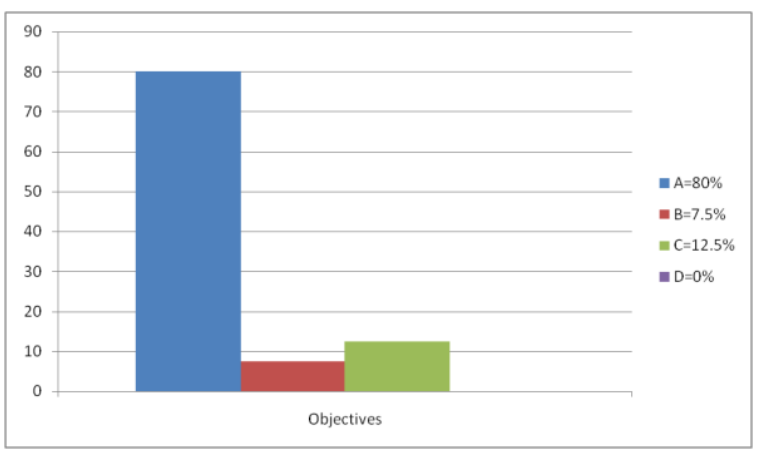

Figure - 3 (Source: We have written this)

The above graph (Figure-3)shows that the maximum number of studies, around $80 \%$ 
spotlighted on conceptual contributions to subject (A), following them $12.5 \%$ focused on present case studies (C) and rest of them 7.5\% related to literature review (B). Studies which did not fall in any of the mentioned categories put into the category 'Non-applicable' (D).

Gap 3: There is a requirement of more research articles related to literature review and case studies which will be helpful as an exploratory study for further research on the subject area.

4. Main Subject: The fourth classification highlighted the main subjects which were core analyzed in the research articles. The coding of subjects are explained in following way -

A-Related to access awareness level of menstrual hygiene

B- Related to menstruation

C- Related to menstrual hygiene management

D -Related to social and cultural beliefs of menstruation

E-Related to attitude of adolescents towards menstruation

$\mathrm{F}$-Related to reproductive health education.

G-Non-applicable

The presentation of codes into graph is explained below -

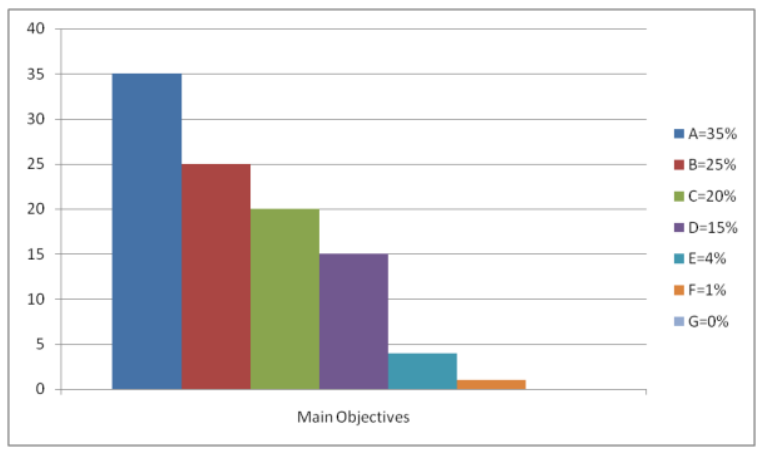

Figure-4 (Source: We have written this)

The Figure-4 explains that $35 \%$ research articles are related to awareness of menstrual hygiene practices(A), $25 \%$ studies are on menstruation (B), $20 \%$ research articles show the picture of menstrual hygiene management (C), $15 \%$ articles are related to social and cultural beliefs of menstruation, $4 \%$ related to adolescent's attitudes and rest $1 \%$ related to reproductive education in schools. From above classification researchers identified major gap.
Gap 4: Mostly research articles related to menstrual hygiene but hygiene related initiatives, public participation in MHM and availability of infrastructure related studies are missing. Studies focused on"DO" but how to " $\mathrm{DO}$ ", that is ignored.

5. Theories/Models used: The fifth classification focused on different theories and modelswhich have been used in research articles. The coding is as follows :

A-Grounded theory

B-Health Belief Model

C-Multilevel Health Education Model

D-Social learning

E-Social Cognitive

F-Non- applicable

The explanation through graphs are following

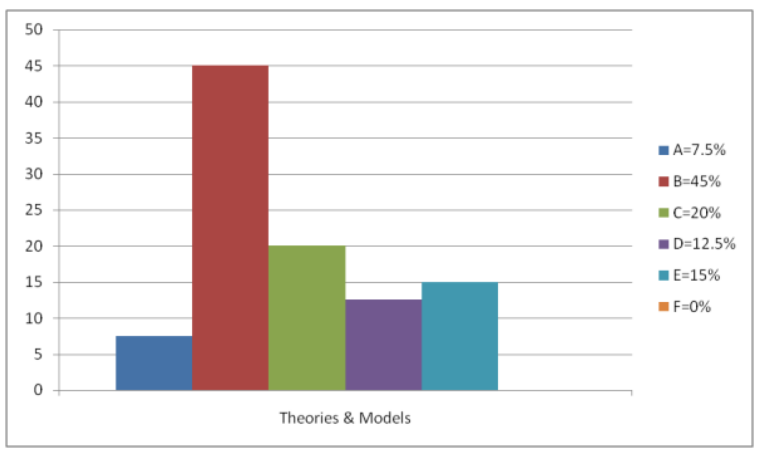

Figure-5 (Source: We have written this)

The study shows (Figure-5) that $45 \%$ research articles related to health belief models(B), 20\% related to multi-level health education model(C), social cognitive theory used in 15 $\%$ different articles, social learning theory used in $12.5 \%$ articles. It was followed by Grounded theory which was used in $7.5 \%$ research articles included in this study.

Gap 5 - Many research articles not indulge any theory or model in studies. For future research, more works need to be done on developing new theories and models.

6. Methods: The sixth category deals with different methods which are used in studied research articles. The coding of different articles are as follows -

A -Cross-sectional study

B - Quantitative

C- Qualitative 
D-Hybrid (Combination of both quantitative and qualitative analysis)

E-Non-applicable

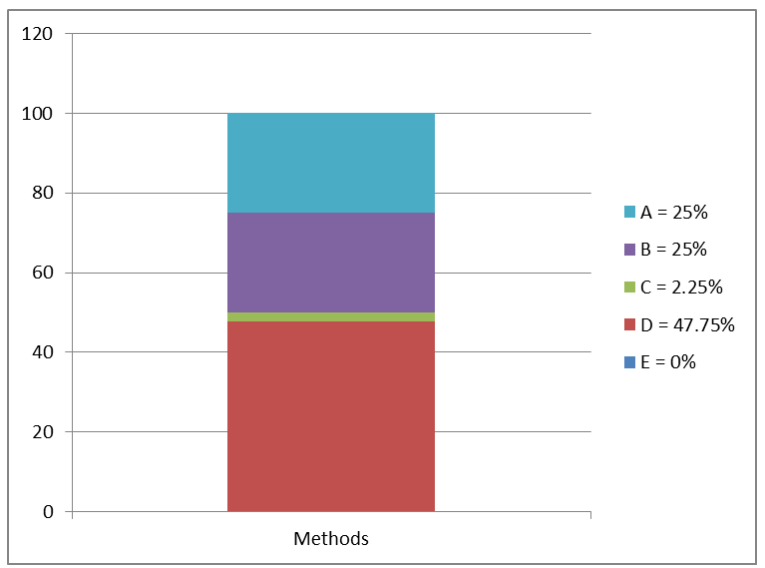

Figure-6 (Source: We have written this)

The Figure-6 explains that $47.75 \%$ research articles have used hybrid method which includes quantitative and qualitative method both. Rest $25 \%$ articles used cross-sectional method (A), another $25 \%$ used quantitative (B) and rest $2.25 \%$ used qualitative methods. Hence qualitative research methods are least used in the available studies.

Gap 6 - Qualitative method is very helpful to enhance different studies in social science. But this method is ignored. It should be considered for making more effective studies.

7. Topics: The seventh category emphasized on the different sub-topics which are used in studied research articles. All sub-topics connected to each other and classified through different codes -

\section{A- Understand Menstrual Hygiene.}

B -Knowledge level from menarche to menopause

C-Analysis perception and attitude towards menstruation.

D-Initiative towards menstrual hygiene practices.

E-To understand social and cultural beliefs for menstruation.

F- Parents belief about menstruation

G-Role of MHM to changing beliefs and perception of adolescents.
H-Parents-Adolescents communication

I-School level awareness mechanism about MHM

\section{J- Others}

The coding explained by below mentioned graph -

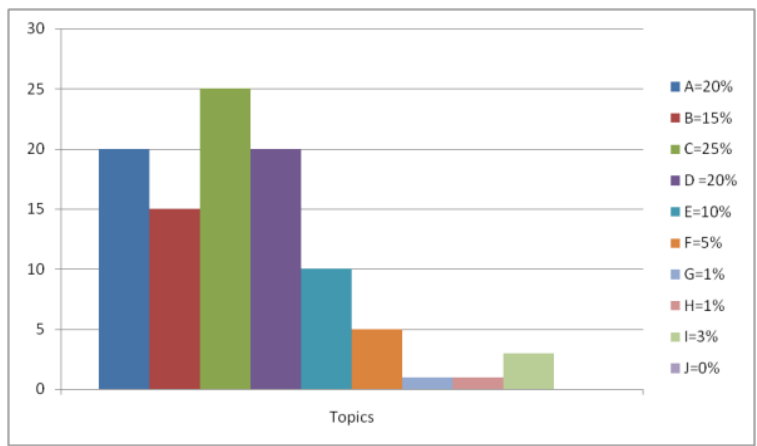

Figure - 7 (Source: We have written this)

The graph explains (Figure-7) that all subtopics are directly or indirectly connected to each other so their ratio is almost equal to one another. There are $20 \%$ research articles related to concept menstrual hygiene (A) and different menstrual hygiene related practices (D), maximum papers $25 \%$ related to perception and attitude towards menstruation (C), $15 \%$ related to awareness level on menarche to menopause (B), $10 \%$ concerned with social and culture beliefs of menstruation, rest following them $5 \%$ concerned with parents beliefs, $3 \%$ school level awareness and rest of them connection of role of MHM with changing society and culture attitude. Above coding shows that one result effects to result of another sub-topic.

Gap 7: There are studies of MHM and attitude of society and culture towards the menstruation but post-effect related studies are missing, means is MHM helps to change positive attitude of society with their culture towards menarche to menopause.

8. Analysis Period : The eighth classification related to analysis of period of the research articles which explained by different codes -
A- Less than 1 years
B-1-2 years
C-3-5 year
D-6 -10 years
E-More than 10 years
F- Non-applicable 
The graph of classification is as follows :

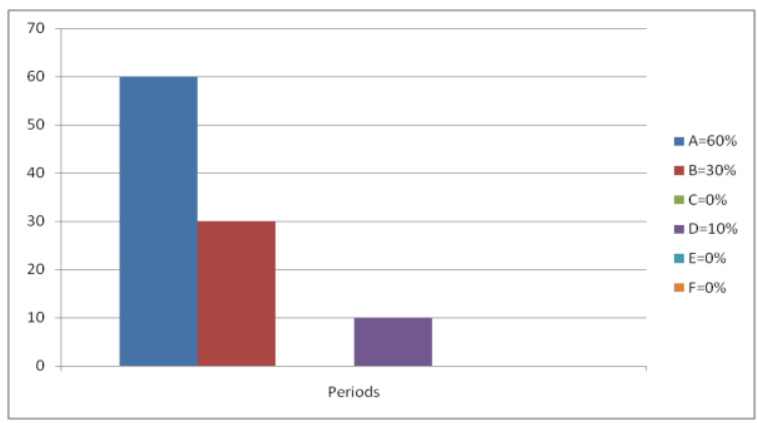

Figure - 8 (Source: We have written this)

The highest number of studies, $60 \%$ related to less than 1 years(A), $30 \%$ related to 1 to 2 years (B) and rest $10 \%$ related to 6 to 10 years which studied for review of literature. But most of the studies did not consider more time spans.

Gap 8 - Large time spans should be considered for further research.

9. Results : This classification analyzed different results which are coded in this way-

A- Proper implementation of MHHM in educational institutions

B- Better communication between teachers and adolescents

C- Promote reproductive health education

D- Communication campaign should be framed with consideration of social and cultural perspectives

E- Menstrual Practices implemented with psychological instinct of adolescents.

F - Others

The classification shown by below graph -

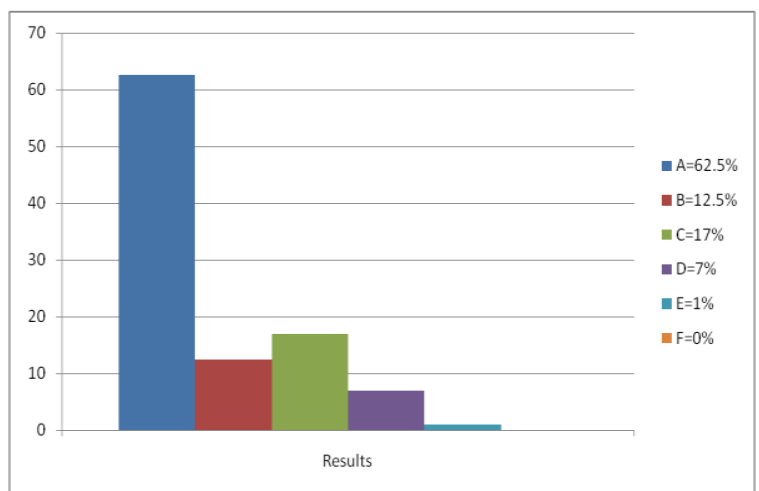

Figure - 9 (Source: We have written this)
The Figure- 9 here explains that maximum percentage $(62.5 \%)$ studies explained that there should be proper implementation of MHHM in schools(A), code B (12.5\%) showed good communication between teachers and adolescents along with $17 \%$ studies analyzed that reproduction education must be promoted in schools $(\mathrm{C})$ and rest of them $7 \%$ (D) highlighted that different communication campaign should be framed according to social and cultural beliefs and least $1 \%$ showed menstrual practices implemented with consideration of attitude of adolescents.

Gap 9 - The major gap explored that menstrual hygiene practices should be implemented at school as well as in houses also. But huge communication gap between adolescents and school administration in terms of menstrual awareness along with MHHM are observed. This creates fear, anxiety and inferiority $\mathrm{d}$ especially among young girls.

\subsection{Conclusions and Recommendations}

The major purpose of conducting this research study to identifying the gap of menstrual hygiene practices in different regions along with different sections. Researchers have analyzed 40 relevant research articles which retrieved from Google scholar and Pub Med from 2007 to 2020. With this in-depth and systematic literature review, researchers have received data on which part of research has already been done and which parts have a potential to work for further research. The researchers have also identified major gaps that will be helpful to set broad line and further roadmap for the study on menstrual hygiene. They also explained the gaps and identified some research agenda where exactly not too much research has been done.

In first classification, researchers have highlighted that menstrual hygiene practices related major studies are conducted in developing countries with the help of developed countries machinery and scholars. But in underdeveloped countries; research part of MHHM is in poor condition. So there should be focus on poorest countries health conditions, because it's a matter of whole reproductive cycle of society.

In second classification, researchers have focused on regions; where research studies are 
going on. Again developed and developing countries performed well, but in developing countries more disparities for research in context of areas and races are distinctly visible. South Asian countries like India and Nepal etc. more studies are conducted by their scholar as well as developed countries scholars but middle and west Asian countries have an orthodox society. There are major psychological and cognitive barriers among adolescents because of that majority of them do not express about their problems openly. On the other side mostly underdeveloped countries/societies from African countries have major economical, educational and ethnic disparities. This disparity works as a barrier in understanding the importance of MHHM. So the researchers here recommended narrative research studies in these countries.

In third classification studied the main objectives of the studies and it highlighted that mostly research articles focused on conceptual subject areas which followed by different case studies but literature review in research articles was missing. Literature review is major part to identifying major gap which set further agenda of research. In developing countries mostly studies are going on conceptual that are not more helpful to highlight ground realities in a very effective way. So the researchers here recommended literature review and comparative studies on the subject area.

In fourth classification, major focus was on main subjects of topic. Around $35 \%$ papers discussed about menstrual hygiene and Menstrual health and hygiene management (MHHM). These menstrual practices have been done in developing countries but these initiatives are in pre and implementing stage. But practical impacts on target audience are not properly evaluated there. Major policies are in final stage and just implementing in some part of major cities but rural and tribal areas are not in importance list and their conditions and circumstances are not much considered during policy making. So we can say area wise major disparities, contribute in creating social and cultural taboo in adolescent minds. Hence researchers recommended further studies should be conducted on practical ways rather than only theoretical parts.
In the fifth classification, researchers have evaluated different theories and models used in research studies. But unfortunately most of the studies conducted in African and some Asian countries have not used or followed any theory or model and written only just conceptual papers. So authenticities of these studies are questioned. On the other side some researchers have used health belief model as well as multilevel health education model for their studies. But mostly scholars ignored social and cultural factors of menstruation. The researchers here recommend social and cultural studies on menstruation and menstrual hygiene.

In the sixth classification, researchers have analyzed different methods which were used in research papers. Scholar used maximum hybrid method encompassing both qualitative and quantitative methods for research. Least number of studies used qualitative method. Hence the researchers here advocated for qualitative studies for further research with content analysis and grounded theory.

The seventh classification focused on the subtopics which were studied in the research articles. It was found that most of the studies indulged in studying attitude and perception towards menstruation. Researchers of different countries have tried to understand diverse menstruation hygiene practices among adolescents. So major focus areas in these studies are menstruation hygiene and belief of adolescents towards MHP. But each society have own culture and social principles and their reactions are dependent on their surroundings. Because of that researchers should analyze different initiatives with consideration of social and culture norms. So the researchers recommended folklore and customs based research for further study.

The eighth classification studied the analysis period of the studies and highlighted that most of the studies didn't consider longer time spans for analysis even though, did not exceeded more than one year. Only in literature review based studies, the time spans were considered from 6 to 10 years. But those numbers of studies are very less. Hence the researchers suggest that further studies need to take longer analysis period of research. 
In the ninth classification, the researchers have studied the different results which they found during analysis of research papers. It was initiated that maximum numbers of studies related to menstrual health and hygiene management and promote sex education in educational institutions. Least studies related to adolescents attitudes and their beliefs. In most of the research papers, scholars have tried to highlight subject area, but they had not reached basic reasons.

Menstruation is a biological process and integral part woman's life. But it has been treated as a societal taboo which has roots in society and culture. It creates anxiety, fear and shame not only in minds of young women but among quinquagenarian women also. So these women disseminate same experience to their daughters. Unfortunately because of communication gap with teachers regarding the menstrual issues creates misunderstanding, misinformation among adolescents. That is the reason why the researchers here recommend that, compulsory reproductive health education should be part of syllabus. Proper sanitation facilities should be provided in schools. This is not the end; there should be continuous interaction of teachers in the presence of health experts and health workers with not only young girls but their mothers too. The interpersonal communication with the pubescent girls will definitely help in elevating the menstrual hygiene among them.

\subsection{Limitations and Future Research Directions of the Study}

The major limitation of this study is Google Scholar. Majority of the research studies for this systematic literature review are retrieved from Google Scholar and PubMed database. The analysis of Scopus and Web of Science database could have given different results what the researchers feel and expect. After going through this study thoroughly the researchers can go further to study the Scopus and Web of Science database. At the same time they can try to retrieve published research works from developed countries and exclusive studies undertaken by the scholars of underdeveloped countries. The researchers can work on application of different theories and models for further studies on menstrual health and hygiene.

\section{REFERENCES}

A. Milan et al. (2019). Public Schools Teenage Girls in Menstrual Hygiene Engagement Sessions: Sharing Experiences with Stakeholders. TOJNED, 9(4), 283-289.

Anand E, et al. (2015). Menstrual hygiene practices and its association with reproductive tract infections and abnormal vaginal discharge among women in India. Sexual \& Reproductive Healthcare, 6(4), 249-254. https://doi.org/10.1016/j.srhc.2015.06.001

Kumar A. \& Srivastava K. (2011). Cultural and Social Practices Regarding Menstruation among Adolescent Girls. Social Work in Public Health, 26(6), 594604. DOI: $\underline{10.1080 / 19371918.2010 .525144}$

A.UU et al (2009). The impact of premenarcheal training on menstrual practices and hygiene of Nigerian school girls. Pan African Medical Journal, 1(2).

Becker MH. (1974). The Health Belief Model and personal health behavior. Health Education Monographs.2, 324-508. [Google Scholar]

Champion V, Skinner CS. (2008).The Health Belief Model. In: Glanz K, Rimer B, Viswanath $\mathrm{K}$, editors. Health behavior and health education. 4, 45-65. [Google Scholar]

C. Susila, John S., K. Satheesh , Precilla (2014). Effectiveness of structured teachingprogramme on menstrual hygiene among the adolescent girls at a selected collegePre-experimental study. International Journal of Comprehensive Nursing, 1(1), 7-13.

Crichton J, et al ( 2012). Mother-daughter communication about sexual maturation, abstinence and unintended pregnancy: Experiences from an informal settlement in Nairobi, Kenya. Journal of Adolescence, 35(1),

21-30. https://doi.org/10.1016/j.adolescence.201 1.06.008

Chinta K et al. (2018).Menstrual Hygiene Patterns and Practices among rural adolescent school girls.Int J Community Med Public Health, 5(12), 5190-5194. DOI: http://dx.doi.org/10.18203/23946040.ijcmph20184788 
Chang, Yu-Ting; Chen, Yueh-Chih (2008). Menstrual Health Care Behavior and Associated Factors among Female Elementary Students in the Hualien Region, Journal of Nursing Research, 16 (1), 8-16.

DOI: 10.1097/01.JNR.0000387285.23065.2d

C. Mouli, Patel (2017).Mapping the knowledge and understanding of menarche, menstrual hygiene and menstrual health among adolescent girls in low and middle income countries. Reproductive Health, 14-30. DOI 10.1186/s12978-0170293-6

Cheraghi, P., Poorolajal, J., Hazavehi, S. M. and RezapurShahkolai, F. 2014. Effect of educating mothers on injury prevention among children aged $<5$ years using the health belief model. Public Health, 128(9), 825-830. doi:10.1016/j.puhe.2014.06.017

Das A. (2014). Sexuality education in India: Examining the rhetoric, rethinking the future. Sex Education, 14, 210-24.

Djalalinia S, Tehrani FR, Afzali HM, Hejazi F, Peykari N. Parents or School Health Trainers, which of them is Appropriate for Menstrual Health Education? Int J Prev Medical, 3(9),622-7. PMID: 23024851; PMCID: PMC3445278.

Dasgupta, M. Sarkar (2008). Menstrual Hygiene: How Hygienic is the Adolescent Girl? Indian I Community Med. 33(2), 7780.DOI: 10.4103/0970-0218.40872

E. Wilson, J. Reeve \& Alice Pitt (2014). Education. Period. Developing an acceptable and replicable menstrual hygiene intervention, Development in Practice, 24(1), 63-80. DOI: 10.1080/09614524.2014.867305

Ekpenyong CE, Davis KJ, Akpan UP, Daniel NE (2011). Academic stress and menstrual disorders among female undergraduates in Uyo, South Eastern Nigeria - the need for health education. Niger J PhysiolSci, 26(2), 193-8. PMID: 22547190.

Griffin MJ.(2012). Health belief model, social support, and intention to screen for colorectal cancer in older African American men. Health Promotion $\mathcal{E}$ Educatio,.51(1),12-22. [Google Scholar]
Garg R, Goyal S, Gupta S.(2012). India moves towards menstrual hygiene: subsidized sanitary napkins for rural adolescent girls-issues and challenges. Matern Child Health J. 16(4), 767-74. doi: 10.1007/s10995-011-0798-5. PMID: 21505773.

Glanz K, Rimer BK, Viswanath K.(2008). Health Behavior and Health Education: Theory, Research, and Practice. New York: John Wiley and Sons.

Haque SE, Rahman M, Itsuko $K$, et al. (2014).The effect of a school-based educational intervention on menstrual health: an intervention study among adolescent girls in Bangladesh. BMJ Open 2014; 4:e004607.

Hochbaum, G. Rosenstock, I. and S, K.( 1952). Health Belief Model. United States Public Health Service, Retrieved from http://www.infosihat.gov.my/infosihat /artikelHP/ bahanrujukan

Hennegan J, Shannon AK, Rubli J, Schwab KJ, Melendez-Torres GJ (2019). Women's and girls' experiences of menstruation in lowand middle-income countries: a systematic review and qualitative meta synthesis. PLoS Med, 16(5):e1002803

Jyothi et al. (2019). Menstrual hygiene among school going adolescent girls: An interventional study in Bagalkot city. MedicaInnovatica, 8(1), 1-5.

Jennifer Thomson, Fran Amery, Melanie Channon\& Mahesh Puri (2019).What's missing in MHM? Moving beyond hygiene in menstrual hygiene management. Sexual and

Reproductive Health Matters, 27(1), 12-15, DOI: $10.1080 / 26410397.2019 .1684231$

Julie M. Hennegan (2017). Menstrual Hygiene Management and Human Rights:

The Case for an Evidence-Based Approach, Women's Reproductive Health, 4(3), 212-231 DOI:10.1080/23293691.2017.1388720

Kaur M et al.(2020). Menstrual awareness, Hygiene, Practices and Perception among the adolescent girls of Himachal.Int J Community Med Public Health. 2020 Mar;7(3):1145-1152 http://www.ijcmph.com 
K.Randhir et.al (2017). Knowledge Attitude and Perception of Sex Education among school going adolescents in Ambala, Haryana, India: A Cross- Sectional Study.Journal of Clinical and Diagnostic Research,11(3), LC01-LC04.DOI: 10.7860/JCDR/2017/19290.9338

KuntalaLahiri-Dutt (2014). Medicalising menstruation: a feminist critique of the political economy of menstrual hygiene management in South Asia. Gender, Place $\mathcal{E}$ Culture: A Journal of Feminist Geography, 1-21. DOI: 10.1080/0966369X.2014.939156

K.Kanwaljit et al (2012).Social Beliefs and Practices associated with Menstrual Hygiene among Adolescent Girls of Amritsar, Punjab, India. JIMSA, 25( 2), 69-70.

Kumar A, Srivastava K.(2011). Cultural and social practices regarding menstruation among adolescent girls. Soc Work Public Health, 26(6), 594-604. doi: 10.1080/19371918.2010.525144. PMID: 21932979

K.M.Agnes (2008).Traditional menstrual practices: sexual and reproductive health and gender implications for adolescent girls.Institute of African Studies Research Review, 24(1)

Lawn UM et al. (2010). Menstruation and Menstrual Hygiene amongst Adolescent School Girls in Kano, Northwestern Nigeria. African J. Reprod. Health, 14(3), 201-207

M. Arundati (2019). Constrained Choices? Menstrual Health and Hygiene Needs among Adolescents in Mumbai Slums. Indian Journal of Gender Studies, $26(1 \& 2)$ 12-39, DOI: 10.1177/0971521518808104

M.A. Mohammad et al (2018).Effective factors on menstrual health among female students in Bam city: a qualitative study. Electronic Physician, 10(2), 6310-618. DOI: http://dx.doi.org/10.19082/6310

MarniSommer, Nana Ackatia-Armah, Susan Connolly \& Dana Smiles (2014). A comparison of the menstruation and education experiences of girls in Tanzania, Ghana,Cambodia and Ethiopia, Compare: A Journal of Comparative and International Education,
45(4), 589-609. DOI: 10.1080/03057925.2013.871399

Misra P, Upadhyay RP, Sharma V, Anand K, Gupta V (2013). A community-based study of menstrual hygiene practices and willingness to pay for sanitary napkins among women of a rural community in northern India. Natl Med J India. 26(6), 335-7. PMID: 25073990

M. Njeri (2007).Factors inhibiting educated mothers in Kenya from giving meaningful sex-education to their daughters.Social Science $\mathcal{E}$ Medicine, 64 (5), 1079-1089. https://doi.org/10.1016/j.socscimed.2006. $\underline{10.008}$

McLeroy KR, Bibeau D, Steckler A, Glanz K.(1988). An ecological perspective on health promotion programs. Health Educ Q Winter, 15(4), 351-77. doi: 10.1177/109019818801500401. PMID: 3068205.

Mukherjee et al. (2020). Perception\& Practices of Menstruation restrictions among urban adolescent girls and women in Nepal: A cross -sectional survey. Reproductive Health 17:81 https://doi.org/10.1186/s12978-02000935-6

N. Dipali, A. Seema, G.Rupali (2009).Impact of health education on knowledge and practices about menstruation among adolescent school girls of Kalamboli, Navi-Mumbai.Health $\mathcal{E}$ Populationperspectives, 32(4), 167175.http:/ / www.nihfw.org

O. Kelly \& G. Sheila (2010). Adolescent Girls Define Menstruation: A Multiethnic Exploratory Study, Health Care for Women International, 31(9), 831-847, DOI: $10.1080 / 07399331003653782$

O. Williams, E.M.Swierad (2019).A Multisensory Multilevel Health Education Model for Diverse Communities. Int J Environ Res Public Health,16(5), 872.doi: $\underline{\text { 10.3390/16050872 }}$

Penelope A. Phillips-Howard, Bethany Caruso,et. al (2016). Menstrual hygiene management among adolescent school girls in low- and middle-income countries. Global Health Action, 9(1), 33032. DOI: $10.3402 /$ gha.v 9.33032 
P Shah Shobha, et al (2013). Improving quality of life with new menstrual hygiene practices among adolescent tribal girls in rural Gujarat, India, Reproductive Health Matters, 21(41), 205-213, DOI: 10.1016/ S0968-8080(13)41691-9

PEARSON, J., \& MCPHEDRAN, K. (2008). A literature review of the non-health impacts of sanitation. Waterlines, 27(1), 48-61. Retrieved February 7, 2021, from http://www.jstor.org/stable/24684955

Pandey Neelesh (2020). Communicating about menstruation to adolescent girls. Mass Communicator: International Journal of Communication Studies, 14(2), 26-30. DOI: $\underline{10.5958 / 0973-967 X .2020 .00009 .5}$

R. Astha et al. (2019). How does a Social and Behavioral Change Communication Intervention Predict Menstrual Health and Hygiene Management: A CrossSectional Study. BMC Public Health, 19:1039. https://doi.org/10.1186/s12889019-7359-z

Rajagopal S, Mathur K (2017). Breaking the silence around menstruation: experiences of adolescent girls in an urban setting in India. Gender Develop, 25(2), 303-17.

Ramathuba, D.U.(2015). Menstrual knowledge and practices of female adolescents in Vhembe district, Limpopo Province, South Africa. Curationis, 38(1), 1551-1557. http://dx.doi.org/10.4102/ curationis.v38i1.1551

Rani S.P.(2014). Knowledge and Practice of Menstrual Hygiene among Married Adolescents and Young Women in Chittoor District of Andra Pradesh, India. Journal of Nursing and Health Science, 3(2),5-16. www.iosrjournals.org

Garg, R., Goyal, S. \& Gupta, S.(2012). India Moves Towards Menstrual Hygiene: Subsidized Sanitary Napkins for Rural Adolescent Girls-Issues and Challenges. Matern Child Health J 16, 767774. https://doi.org/10.1007/s10995-011$\underline{0798-5}$

Rosenstock, 1. \& Stretcher, V. (1988). Social learning theory and the health belief model. Health Education Quarterly, $15,175-183$
Stuart, R. (1989). Social learning theory: A vanishing or expanding presence? Psychology, A Journal of Human Behavior, 26, 36-47

Sharma Shantanu et.al (2020).Menstrual hygiene preparedness among schools in India. Int. J. Environ. Res. Public Health,17, 647, DOI: 10.3390/ijerph17020647.

Setyowati, S., Rizkia, M., \&Ungsianik, T. (2019). Improving Female Adolescents' Knowledge, Emotional Response, and Attitude toward Menarche following Implementation of Menarcheal Preparation Reproductive Health Education. Asian / Pacific Island Nursing Journal, $\quad 4(2)$. https://kahualike.manoa.hawaii.edu/ap in

S. Farhana et al. (2019). A Study on Assessment of Knowledge of Reproductive Health Education among the Students of Jammu Region, J\&K .International Journal for Research in Applied Sciences and Biotechnology, 6(4), 2128. https://doi.org/10.31033/ijrasb.6.4.6

Sharma, Nidhi \& Nahak, Fakira \& Kanozia, Rubal. (2019). Identifying the Gaps of Health Communication Research: A Systematic Review. Journal of Content, Community and Communication, 10(5), 123140. DOI 10.31620/JCCC.12.19/13.

Siabani S, Charehjow H, Babakhani M (2018). Knowledge, Attitudes and Practices (KAP) Regarding Menstruation among School Girls in West of Iran: A Population Based Cross-Sectional Study. Int J Pediatr, 6(8), 8075-85. DOI: 10.22038/ijp.2018.28633.2495

Santhya, K.G. et al (2017).Understanding the lives of adolescents and young adults (UDAYA) in Bihar, India. New Delhi: Population Council.

Singh et al (2011). Menstrual Hygiene Practices and RTI among ever-married women in rural slum. Indian Journal of Community Health, 22(2),41-43. https://www.researchgate.net/publicati on $/ 266228116$

T. B. V. Crystal (2018). Improving menstrual hygiene management in emergency contexts: literature review of current 
perspectives. International Journal of Women's health, 10. 169-186. http://dx.doi.org/10.2147/IJWH.S13558 $\underline{7}$

Upashe et al. (2015). Assessment of Knowledge and Practice of menstrual hygiene among high school girls in Western Ethiopia. BMC Women's Health, 15:84. DOI 10.1186/s12905-015-0245-7

Verma P.et al (2013). Knowledge and practices about menstrual hygiene among higher secondary school girls, Indian Journal of Community Health, 25(3), 265-271.

World Health Organization. Adolescent friendly health services. An agenda for change. Geneva: World Health Organization, 2002.

Y. Arpana (2016). Mis-fitting Menstrual Hygiene Products: An Examination of Advertisements to Identify Gaps in the Diffusion of Innovation. IAFOR Journal of Psychology \& the Behavioral Sciences, 2(3), 33-45.

Zaidi SHN, Sivakami A, Jegadeesh Ramasamy D. (2015). Menstrual hygiene and sanitation practices among adolescent school going girls: a study from a South Indian town. Int J Community Med Public Health, 2, 189-94. 